5. LA DINÁMICA DEL PODER EN LA TRANSICIÓN POLÍTICA DE 1820

BLANCA ESTHER BULDAIN JACA

UNED 



\title{
5. LA DINÁMICA DEL PODER EN LA TRANSICIÓN POLÍTICA DE 1820
}

\author{
POR \\ BLANCA ESTHER BULDAIN JACA
}

UNED

El nuevo régimen político, que se instaló a partir del 7 de marzo con el triunfo de la revolución, contó en la cúspide del poder con un Rey, al que no le quedó más remedio que admitirlo por la fuerza, poco o nada dispuesto a colaborar en su implantación, con un gobierno primero a la medida del Monarca y del régimen derrocado, después a la del nuevo régimen, y con la Junta Provisional encargada de realizar la transición. El ejercicio del poder, por tanto, se vio directamente influido por la actitud de cada una de las partes, de las relaciones muchas veces dificiles entre ellas y de la supremacía que cada una quiso dar de sí misma y de los demás ante las restantes y la opinión pública.

En este juego de poder tomaron parte, indirectamente y en la medida en que influyeron en las decisiones, las Juntas provinciales creadas en distintos puntos de la Península a partir de febrero para implantar en su ámbito el régimen constitucional y no cejar hasta verlo instituido en todo el país con la reunión de Cortes. Por su parte las Sociedades Patrióticas, con menos posibilirades de presión que las Juntas por su carácter más popular y menos institucionalizado, intentaron, y en ocasiones lo lograron, que el ritmo de las reformas y la profundidad de éstas se acomodaran a sus deseos. No podía ser de otra forma en un régimen en el que la libertad de expresión era un pilar fundamental y la opinión pública el reflejo de este derecho al que el poder no pudo sustraerse por más que lo intentó cuando no le convino. Finalmente, el ejército sublevado constituyó el tercer «grupo de presión» por el prestigio alcanzado como brazo ejecutor de la revolución y como sostén del nuevo sistema.

Algunos autores han afirmado que en estos primeros momentos del Trienio, la actitud de Fernando VII fue, si no de alegre, si de sincera aceptación de los hechos. Estos autores interpretan la famosa frase de su Manifiesto "marchemos francamente..." como muestra de la buena voluntad 
del Monarca ${ }^{1}$. Otros ven precisamente en esta afirmación, teniendo en cuenta posteriores sucesos, la muestra fehaciente de su felonía ${ }^{2}$. A la luz de la documentación consultada para este trabajo puede afirmarse que ambos puntos de vista son inexactos. El Rey no fue totalmente sincero al manifestarse como adalid del nuevo sistema, ni totalmente hipócrita. No fue el primero en marchar por la senda constitucional, pero tampoco realizó por el momento acciones positivas para borrarla.

Entre el abierto enfrentamiento y la actitud claramente favorable, optó por la vía intermedia de esperar mejores tiempos y ayudar a ello en lo posible. Tal afirmación no es gratuita si se analizan las dos fases por las que atravesó la conducta del Rey en estos primeros meses. La primera de ellas cubrió la etapa comprendida entre el juramento y la convocatoria a Cortes (del 9 al 22 de marzo) y la segunda desde ésta hasta su reunión solemne el 9 de julio. La primera se caracterizó por la resistencia a tomar medidas que abocaran irremediablemente a la Monarquía a un régimen, aceptado aunque no deseado por Fernando VII, cuyo futuro era imprevisible entonces. Esta obstrucción inicial dio paso en la segunda fase a la resignación y a la indiferencia como actitudes predominantes en él ${ }^{3}$.

1 Manifiesto del Rey a la Nación. Madrid 10 de marzo de 1820. ARCHIVO DEL CONGRESO (citado a partir de ahora con las siglas AC), t. 36, 7-8. Gaceta Extraordinaria, 12 de marzo de 1820, n. 37, 263-264. Fue recibido por la Junta con entusiasmo en la sesión de tarde del 12 de marzo, AC, t. 35, 17, publicado en Manuel Pando Fernandez de Pinedo, Marqués de Miraflores: Documentos a los que se hace referencia en los Apuntes históricos-críticos sobre la Revolución de España. Londres, Oficina de Ricardo Taylor, 1834, t. I, 91-92. La aceptación, a gusto o disgusto, por parte de Fernando VII, de las condiciones impuestas por el régimen constitucional, es un extremo dificil de discutir, y son los historiadores liberales los primeros en jactarse de ella. Las fuentes realistas que no se escandalizan del hecho de que el Monarca jurase la Constitución, aseguran que «Fernando no fue perjuro». José Luis ComeLLAS GARClaLlefA: El Trienio Constitucional. Madrid, Rialp, 1963, 144-145. La jactancia, no sólo de los historiadores liberales, sino de las propias fuentes, incluidas las emanadas de la Junta Provisional, de la sinceridad del Rey responden más al deseo de inspirar confianza que a una realidad. Por otra parte, el argumento de las fuentes realistas de culpar a los liberales de sus propios males y eximir al Rey de toda responsabilidad, es tan conocido como inexacto. El propio ministro de la Guerra, bien caracterizado por su temple nada exaltado, más bien inusualmente moderado en aquel gabinete, estaba convencido de que el Rey no fue sincero. Pedro Agustín Giron, Marqués de las Amarillas: Recuerdos (1778-1873). Pamplona, EUNSA, t. II, 125. El glosador de estos Recuerdos, a pesar de consignar que los primeros pasos dados por el Rey parecian responder al propósito de atenerse a las nuevas leyes, acaba reconociendo que «Los hechos persuadieron a los Argüelles, Canga y demás ministros... de que el Rey estaba de mala fe". Juan ARzAdun y ZaBALA: Fernando VII y su tiempo. Madrid, Galo Sáez, 1942,140 y 142.

2 José Luis Comellas Garcia-Llera: Los realistas en el Trienio Constitucional (18201823). Pamplona, Editorial Gómez, 1958, 28 y 29. Ante la falta de un estudio sobre la primera actitud del Rey expone las versiones contrapuestas.

${ }_{3}$ El relato minucioso de lo que podía ser el despacho de un ministro con el Rey nos lo ofrece el Marqués de las Amarillas, su preferido en aquel gabinete de «presidiarios". Por más que él se queje, aunque no lo termina de reconcer, era patente la indiferencia real hacia los temas tratados y la constancia de su falta de aprecio e, incluso, desconsideración rayana en la mala educación. Giron, op. cit., t. II, 93-95. 
Por su parte, la Junta Provisional, verdadero poder tutelar en la implantación del Nuevo Régimen ${ }^{4}$, se movió en un doble plano respecto al Rey, según que sus actuaciones tuvieran lugar en la esfera reservada o trascendieran a la opinión pública. En la diaria discusión de los problemas de gobierno se puso de manifiesto con toda evidencia la enorme desconfianza de la Junta en la intención y actuación real. No perdió, sin embargo, oportunidad de mostrar una imagen favorable, de tal forma que tan reiterada insistencia sería suficiente, si no para demostrar, sí para sospechar que detrás de tanta loa lo que realmente se escondía era precisamente la desconfianza que se quería ahuyentar. El prestigio de la realeza y la negativa del liberalismo moderado a prescindir de la Monarquía fueron razones de mucho peso en semejante actitud.

Lentamente, conforme se fue afianzando el sistema, la Junta se sintió más segura y disminuyeron las muestras de desconfianza en el Rey, al tiempo que aumentaba la indiferencia de éste. Las dos actitudes corrieron paralelas pero en sentido contrario. En estas circunstancias, con puntos de partida e intereses claramente distintos, las relaciones entre la Junta y el Rey ni podian ser ni fueron fáciles. Nunca se llegó al choque frontal y público, pero frecuentemente se produjeron episodios de tensión y forcejeo en los que cada parte dejó traslucir su posición con tanta mayor claridad cuanto más dispares fueron sus puntos de vista.

Desde los inicios de su actuación, la Junta pudo comprobar que el Rey no estaba dispuesto a ponerse a la cabeza del nuevo sistema, sino a retrasar en lo posible su normalización. Esto se puso de manifiesto con dos temas vitales: el nombramiento del nuevo gobierno y la comunicación oficial del cambio de régimen a las potencias exteriores. La Junta esperó lo que creyó un tiempo prudencial para que Fernando VII ejerciera sus funciones constitucionales, pero la propia resistencia del Rey a realizar el cambio de gobierno lo antes posible con personas adecuadas a las nuevas circunstancias condujo a la Junta a una actuación a todas luces inconstitucional ${ }^{5}$. De esta manera la dinámica de obstrucción por un lado e ilegalidad por otro quedó instalada en el Trienio desde el principio, para adquirir más tarde caracteres virulentos. No fue, por tanto, casualidad que, al mismo tiempo que la Junta tomó el acuerdo de indicar al gobierno la necesidad de que el Rey se rodeara de personas "de probidad", lo hiciera

4 Creada el 9 de marzo por Real Decreto, tuvo todas las facultades de hecho para ejercer el poder en tanto se reuniesen las Cortes. Véase Blanca Esther BULDAIN JACA: "La Junta Provisional de 1820: instalación y atribuciones" en Revista de Historia Contemporánea, n. 1, Sevilla 1982, 39-64.

5 Tras varias indicaciones verbales y escritas sobre la necesidad de rodearse de "personas de probidad y buen concepto público", la Junta Provisional se vio obligada a dar los nombres que se debian nombrar para Gobernación de la Península, Hacienda, Gracia y Justicia y Marina. Exposición del 22 de marzo de la Junta Provisional a S.M. AC, t. 41, 412413; t. 35,64 y 67 , sesiones de tarde del 21 de marzo y de mañana del 22. ARCHIVO GENERAL DE PALACIO, Papeles Reservados de Fernando VII, t. 38, n. 23, 5 y 6. 
también para que se comunicara a embajadores y ministros el juramento real ${ }^{6}$. Tampoco lo fue la coincidencia en fechas, 22 de marzo, del decreto de convocatoria a Cortes, la propuesta por la Junta de nombres concretos, que fueron definitivos, para el nuevo gobierno y la circular del 23 a los embajadores con la comunicación oficial ${ }^{7}$.

Tampoco faltaron las ocasiones en las que la soterrada resistencia dio paso al claro enfrentamiento. Existen dos casos notables entre varios otros. La Junta expresó directamente sus sospechas acerca de las intenciones de Francia con motivo de las noticias sobre la llegada del Marqués de Latour du Pin como enviado especial y el deseo de que se evitara ${ }^{8}$. Esto provocó el disgusto del Monarca que se sintió directamente aludido, manifestó su buena disposición para «caminar por la senda constitucional» y el deseo de recibir al diplomático francés, a no ser que la Junta se opusiese, en cuyo caso «hará ese sacrificio" " ${ }^{9}$. La Junta se disculpó pero reiteró su proposición y pidió que se diesen instrucciones al embajador en París para evitar que se presentase en Madrid cualquier enviado que «parezca sospechoso" ${ }^{10}$. La desconfianza en la sinceridad del Rey y la advertencia sobre supuestas veleidades quedaron patentes. El otro conflicto, sobre los miembros que debian componer la Junta nacional del Crédito Público, surgió del empeño real por nombrar un tercer ministro como estaba legislado por las Cortes de Cádiz y del deseo de la Junta Provisional de no sustituir a Miguel Lobo, que habia fallecido, hasta la reunión de Cortes, con el argumento legal de la competencia exclusiva de la representación nacional ${ }^{11}$.

- AC, t. 35, 12 y 12v, sesión de mañana de 11 de marzo.

- Circular del Rey a sus representantes cerca de las demás potencias. AC, t. 36, 19$22 v$.; t. 35,74 y $81 v$., sesiones de tarde de 24 y 26 de marzo.

- La Junta estaba convencida de que el objeto del viaje del Marqués de Latour du Pin, ministro plenipotenciario de Francia en Holanda, sin carácter oficial era influir cerca del Rey contra el sistema constitucional. Exposición del 2 de abril de la Junta a S.M. AC, t. 36, 42-43; t. 35, 98v., sesión de tarde del 1 de abril. El embajador británico en Madrid, Sir Charles Stuart, se encargó de dar a conocer oficiosamente la comisión del enviado: entregar una carta a Fernando VII aconsejando la adopción de un sistema calcado de la Carta francesa. Guillaume de Bertier de Sauvigny: Metternich et la France après le Congrès de Vienne. Paris, Hachette, 1968-1970, t. II, 308.

- El ministro se quejó también a la Junta por estas reticencias y aconsejó permitir la venida del enviado francés. Oficio de Juan Jabat a la Junta el 3 de abril manifestando el disgusto de S.M. AC, t. 36, 33-40; t. 35, 102v-103v, sesión de mañana del 3 de abril.

10 Oficio del 3 de abril de la Junta al Ministro de Estado con los medios para evitar la ingerencia francesa. AC, t. 36, 28-29v.; t. 35, 104v y 105, sesión de tarde del 3 de abril.

${ }_{11}$ «Decreto XCVI para la creación de una Junta nacional de Crédito Público, en lugar de la Consolidación de vales reales", 26 de septiembre de 1811 en Decretos de las Cortes, t. II, 2 y 3. «Orden con el nombramiento de los individuos de la Junta nacional del Crédito Público", 15 de octubre de 1811 en Decretos de las Cortes, t. III, nota segunda (correspondiente al t. II, 16). Comunicación del 27 de marzo del ministro de Hacienda a la Junta expresando el deseo de S.M. de nombrar al tercer Director del Crédito Público. AC, t. 39, 101-102; t. 35, 85 y $85 \mathrm{v}$., sesión de mañana del 28 de marzo. Un tercer Director nombrado por el Rey no convenía para despertar la confianza de los acreedores del Estado, acostumbrados durante largo tiempo a ver cómo los caudales que debian destinarse al pago de los intereses se empleaban sistemáticamente en los gastos corrientes de Hacienda. 
Esta razón no convenció al Rey quien acudió al artículo 171 de la Constitución para reclamar el absoluto nombramiento de los empleados civiles que no estuviesen expresamente derogados y dejar constancia de que cumplía con su deber cualquiera que fuese la decisión de la Junta. En este caso manifestó, en tono amenazador, que haria presente a las Cortes su protesta porque se le negaba el ejercicio de sus facultades constitucionales ${ }^{12}$. La Junta dio la callada por respuesta.

En todos los ejemplos anteriores, aunque no únicos, prevaleció la voluntad de la Junta sobre la del Rey. A éste no le quedo más remedio que ceder $y$, a pesar de que aquélla no hizo ostentación de su triunfo, asumir su derrota con manifiesto desagrado. Los triunfos del Rey, cuando los hubo, fueron de menor cuantía y en ellos la Junta no tuvo inconveniente en ceder sin problemas. Tal ocurrió con el juramento de la Constitución por los Infantes y la Junta que tuvo lugar el 14 de marzo y no el 19, aniversario de la misma, por expreso deseo real ${ }^{13}$. La Junta se plegó a la decisión de Fernanado VII de no incluir a los obispos, diputados de las Cortes de 1814, que firmaron el Manifiesto llamado «de los Persas», en el Real Decreto de 15 de marzo que ordenaba la reclusión de todos ellos en monasterios o conventos como habia propuesto la Junta, so pretexto de medida precautoria, no judicial, por lo que no se quebraba la igualdad ante la ley ${ }^{14}$.

En otras ocasiones el Rey ensayó, a veces con resultado, el método de dejar para las próximas Cortes aquellos temas en los que no le gustaba

12 Resulta inevitable para el historiador que, a la vista de este antecedente, acuda a su memoria el famoso incidente de la "coletilla» del año siguiente. Fue el cumplimiento de una amenaza anunciada. Oficio del 29 de marzo del ministro de Hacienda a la Junta dando cuenta a la opinión de S.M. acerca del tercer Director del Crédito Público. AC, t. 39, 235-238,; t. 35, 97, sesión de mañana del 1 de abril.

${ }_{13}$ La Junta encargo a su vicepresidente, el general Ballesteros, que consiguiera de Fernando VII dia y hora para el juramento. AC, t. $35,15 \mathrm{v}$., sesión de mañana del 12 de marzo. Al dia siguiente elaboro una minuta para que fuese el 19, aunque sin presionar, puesto que lo dejó a su elección. AC, t. 35, 19v., sesión de mañana del 13 de marzo; t. 36, 154 y 154v. Ese mismo dia fueron convocados para el 14 a las doce de la mañana. AC, t. 35, 23v., sesión de mañana del 14 de marzo.

${ }_{14} \mathrm{AC}, \mathrm{t} .36,398-404$. La discusión del tema en el seno de la Junta provocó ciertas discrepancias. Los miembros eclesiásticos de la misma, esto es, el Presidente Cardenal Borbón y el Obispo de Michoacán, junto con Pezuela opinaron que no se debía pedir explicaciones por el decreto. El Cardenal añadio, además, que si se pedían, el oficio lo debía firmar el Vicepresidente como asi fue. No quisieron verse personalmente involucrados en un tema de reclusión de altas jerarquías eclesiásticas. $A C, t .35,270 v$., sesión de mañana del 20 de mayo. En cambio Vicente Sancho, cuando la Junta acordó "que no se le ocurre añadir reflexión alguna" a la negativa del Rey, siguió insistiendo en que no habia razón para hacer diferencias entre los diputados «persas». AC, t. 35,281 , sesión de tarde de 23 de mayo. La Junta presionó al Rey únicamente para que, tomada la decisión de recluirlos, no se hicieran excepciones y todos fueran tratados por igual, pero la iniciativa no fue de la Junta como afirma Maria Cristina, DIz-LoIS: El Manifiesto de 1814. Pamplona, EUNSA, 1967, 176 y 177, sino del ministro de Gracia y Justicia, García Herreros, presionado por las Sociedades Patrióticas. «Memoria leída en las Cortes por el Sr. Secretario del Despacho de Gracia y Justicia en la sesión de 12 de julio de 1820", Madrid, 11 de junio de 1820, en Diario de Sesiones, 12 de julio de 1820, n. 8 (apéndice segundo), 67. 
o convenía la propuesta de la Junta y que competian a la representación nacional. Utilizó todos los recursos a su alcance para evitar la devolución al Crédito Público de los bienes de la Compañía de Jesús: desde no contestar a la exposición de la Junta que suscitaba el tema, hasta pasarla a consulta del Consejo de Estado con grave disgusto de aquella, posponer el problema hasta las Cortes y, finalmente, dar la callada por respuesta ${ }^{15}$. Tampoco faltó por parte del Rey el intento de gobernar con todas las facultades que la Constitución le permitía. Ensayó sin resultado medidas y nombramientos, calificables de descabellados en aquel momento. El correspondiente ministro se encargó de hacerle ver su inconveniencia e inutilidad ${ }^{16}$.

A pesar de que las relaciones de la Junta con el Rey no fueron idílicas, sin embargo, se puede hablar de cuidado y ponderación por parte de aquélla. Hubo ocasiones en que tuvo que hacer oídos sordos a opiniones más radicales y romper una lanza en pro de la dignidad del Rey. Con motivo de los rumores sobre la preparación de un complot en el que se incluia la fuga de Fernando VII y de toda la familia real, los ministros pidieron consejo a la Junta sobre la necesidad de que el Rey lo desmintiese, a lo que se negó rotundamente ${ }^{17}$.

Tampoco consintió que nadie dudara de la buena voluntad del Rey, ni siquiera los ministros, a excepción de ella misma. Así evitó medidas que lo pusieran de manifiesto o tomó otras para afianzar esta creencia. Cuando el ministro interino de la Guerra, Ramón Zarco del Valle, nada sospechoso de radical por otra parte, propuso a la Junta la conveniencia de mandar personas de "notorio mérito y crédito" con los pliegos de la convocatoria de Cortes para inspirar confianza, aquélla contestó que de ninguna manera, pues consideraba suficiente los correos extraordinarios y "la marcha firme del Rey» ${ }^{18}$. Tampoco tuvo inconveniente en manifestar a la de Aragón que

15 La exposición de la Junta de 27 de marzo estaba todavía el 13 de abril esperando el parecer del Consejo de Estado y fue contestada definitivamente por el Rey el 29 del mismo mes. El tema languideció hasta el 10 de mayo, última referencia de la Junta, en que se dejo de aludir al mismo AC, t. 36, 253-259v. y 352-353; t. 35, 82-83, 121, 143v., 153v., 211, 229,241 y $241 v$., sesiones de mañana del 27 de marzo y 8 de abril y de tarde del 13 y 15 de abril y del 1,7 y 10 de mayo.

${ }_{16}$ «El Rey Fernando tascaba mal el freno que, con su falsa política antes, y con su debilidad después, se había dejado poner: y oyendo las sugestiones de hombres tan apasionados como ignorantes de las cosas de gobierno, pretendia se dictasen medidas o se hiciesen nombramientos en el momento imposibles" como el traslado de la Brigada de Carabineros Reales de Córdoba a la capital o el nombramiento del General Imaz para Gobernador de Madrid, GIRON, op. cit., t. II, 114-115.

17 Para la Junta, que de ninguna manera dio crédito a estos rumores, una declaración del Rey hubiera supuesto además de comprometer su decoro, una medida innecesaria $e$ inconveniente por «inútil o insuficiente". Inútil para quienes no creyesen en semejantes rumores e insuficiente para aquellos que creyendo en ellos verian en la medida la forma de dar confianza y asegurar mejor el proyecto. AC, t. 40, 325-335v.; t. 35, 382-388v., sesión de tarde del 23 de junio.

18 AC, t. 40,579-580v.; t. 35, 65v.-66, sesión de mañana del 22 de marzo. 
habia ejercido plenamente su poder constitucional nombrando todos los funcionarios públicos y dictando las medidas que le competian como jefe supremo de la Nación ${ }^{19}$. Por otra parte, en cambio, le pidió a Fernando VII que declarara solemnemente su satisfacción a las tropas, pueblos y Juntas que se habian adelantado en el juramento de la Constitución ${ }^{20}$, cuando, siguiendo su anterior razonamiento, hubiera bastado observar la franca actuación del monarca. Públicamente se guardaron las formas, aunque privadamente fue la Junta provisional quien ejerció las facultades constitucionales de un Rey anticonstitucional.

Si el Rey desempeñó el papel más desagradaable en la cúpula del poder, al Gobierno, cualquiera de los tres que hubo, le tocó jugar el más deslucido. Aunque por la Constitución los ministros eran responsables de las decisiones que adoptasen en su respectiva Secretaria del Despacho, sin embargo, carecieron casi por completo de autoridad. Su competencia quedó reducida, de hecho, a consultar a la Junta cualquier asunto y a cumplir sus resoluciones. Sólo tuvieron libertad de actuación en cuestiones de trámite y en la preparación de los trabajos para las futuras Cortes. De esta forma, la Junta se constituyó en una institución tutelar no sólo para el Rey, sino para el Gobierno, e incluso para el Gobierno constitucional elegido por ella misma ${ }^{21}$. Como era de esperar, las relaciones entre la Junta y el Gobierno heredado del Antiguo Régimen, no pudieron ser cordiales. Los choques y tensiones fueron frecuentes y se vieron, además, agudizados porque precisamente en los inicios del periodo era cuando se tenía que poner en vigor toda la reforma realizada por las Cortes de Cádiz. Fácil es suponer, por otra parte, hacia qué régimen se inclinaba su fidelidad.

Aunque en un primer momento la Junta elaboró tres minutas de decreto para «inspirar a toda la Monarquia una justa confianza en el Gobierno» ${ }^{22}$, desde el principio supo también que gobernar el país con el antiguo Ministerio era inviable. La insistencia en el relevo se debió no sólo al propio convencimiento sino también a la presión que en el mismo sentido

19 Oficio del 5 de abril de la Junta Provisional a la de Aragón sobre inexistencia de influencias negativas en el Rey. AC, t. 41, 167-168; t. 35, 109v., sesión de mañana del 5 de abril.

${ }^{20}$ El acuerdo lo tomó la Junta a propuesta del Obispo de Michoacán. AC, t. 41, 402; t. 35, 38-38v., sesión de mañana de 17 de marzo.

21 El testimonio del ministro de la Guerra, Marqués de las Amarillas, no deja lugar a dudas sobre la superioridad del poder de la Junta cuando afirmo: «... ella, y no S.M. fue el verdadero soberano de España, puesto que habia jurado no solo gobernar con su acuerdo, sino no hacer nada contra su parecer." GIRÓN, op. cit., t. II, 98.

${ }_{22}$ Estas minutas se referlan a la separación de la Tesorerla General del Crédito Público, al restablecimiento de los Ministerios de la Gobernación de la Península y de Ultramar y de las Juntas de censura como en 1814 para que se llevase a cabo la libertad de imprenta, así como una proclama de la Junta sobre este mismo tema. AC, t. 36, 160-162; t. 35, 6-7, 7v. y 8 , sesiones de mañana y tarde del 10 de marzo. 
ejercia desde diversos ángulos la opinión pública ${ }^{29}$. La necesidad de relevar el antiguo gabinete fue ineludible, a pesar del reconocimiento por parte de la Junta de la buena fe de algunos ministros, de su esfuerzo por restablecer cuanto antes el nuevo sistema e, incluso, por anticiparse con la intención, quizás, de permanecer en el cargo ${ }^{24}$.

Además de las fricciones que la Junta protagonizó con el Rey, en las que el Gobierno siempre fue intermediario y partícipe en la medida en que no dimitió con el cambio de régimen, hubo otros enfrentamientos directos con el antiguo Ministerio donde se pone de manifiesto su falta de colaboración. El nombramiento de ministros para el Tribunal Supremo de Justicia, al que procedió el Gobierno sin consultar previamente con la Junta, le obligó a tomar el acuerdo de cambiar la fórmula de las consultas y, posteriormente, a terminar con las comisiones verbales para pasar a hacerlo por escrito ${ }^{25}$. El ministro de Hacienda, González Salmón, deslizó en un oficio a la Junta si debía cumplirse el decreto de las Cortes de Cádiz de 13 de septiembre de 1813, por el que los bienes de la Inquisición debían emplearse en el pago de los intereses de la deuda nacional, ya que nunca llegó a ponerse en vigor. La Junta le contestó destempladamente que el citado decreto no se llevó a efecto por el regreso del Rey y el restablecimiento del Tribunal, no por culpa del Crédito Público ${ }^{26}$. El ministro interino de la Gobernación, José García de la Torre, envió a la Junta el 14 de marzo el expediente y circular elaborados por el Consejo de Castilla en cumplimiento del Real Decreto de 6 de marzo para la celebración de Cortes ${ }^{27}$. Naturalmente la Junta le devolvió

${ }_{23}$ En la Representación a S.M. de 18 de marzo manifestó claramente, por una parte, que los hechos ocurridos desde enero eran un obstáculo insuperable para que los ministros siguiesen en sus funciones y, por otra, que la actitud de las provincias y el lenguaje de las Juntas y de quienes dirigian la opinión pública reflejaban una desconfianza que no desaparecerla hasta que, entre otras cosas, fuese nombrado un gobierno “adicto». AC, t. 41, 405407 ; t. 35, 42 y $42 v$., sesión de mañana del 18 de marzo.

${ }^{24}$ "Manifiesto de la Junta Provisional a las Cortes», en Miraflores, Documentos, op. cit., 123.

25 El decreto aparecido en la Gaceta, n. 39, 271 y 272, el 14 de marzo omitió entre los Ministros del Supremo Tribunal de Justicia a algunos que ya lo fueron en 1814 y nombró otros que no merecian confianza, a pesar de la advertencia de la Junta el día anterior. Este hecho obligó a una rectificación posterior. Por si ya fuera poco el disgusto de la Junta, varios ciudadanos de Madrid en una Exposición del 14 de marzo rubricada con treinta y nueve firmas, le acusaban de equivocaciones y falta de energía, entre otras cosas, por estos nombramientos del Tribunal Supremo de Justicia «que han tratado de comprometer a S.M." AC, t. 41, 300304 ; t. 35, 23v. y 24, sesión de mañana del 14 de marzo. Los acuerdos precautorios se tomaron en las sesiones de mañana del 14 y 17 de marzo, AC, t. 41, 401 y 403; t. 35, 23v., 24 y $37 v$.

${ }_{26}$ Oficio del ministro de Hacienda a la Junta del 13 de marzo, AC, t. 39, 124-125 y Contestación al ministro del 17 de marzo, AC, t. 39, 126-128v.; t. 35, 37 y 42, sesiones de mañana del 17 y 18 de marzo.

${ }_{27} \mathrm{AC}, \mathrm{t} .40,499 ; \mathrm{t} .35,27$, sesión de mañana del 15 de marzo. El documento se refiere al decreto de 8 de marzo, pero forzosamente tiene que tratarse del decreto del día 6 , único que ordenaba al Consejo de Castilla tomar las medidas necesarias para la celebración de Cortes. Gaceta E., 7 de marzo de 1820, n. 30, 237. Si por el contrario la fecha es correcta, quiere decir que el Consejo redactó a pesar de todo el proyecto que se encargó el 6 de marzo como si el decreto del 7 no significase la ruptura total con el Antiguo Régimen y sus instituciones. 
los documentos diciendo que ya había adoptado sus propios acuerdos ${ }^{28}$ muy alejados, claro está, de una convocatoria a Cortes tradicionales. Este envío estaba, ni siquiera como antecedente, fuera de lugar, a no ser que a esas alturas el gobierno de Fernando VII pretendiera solapadamente el mantenimiento del Antiguo Régimen.

El 18 de marzo la Junta llamó enérgicamente la atención del ministro de la Gobernación en dos aspectos fundamentales: publicar todas la noticas referentes a la reposición de las instituciones constitucionales y acelerar los trabajos conducentes a ese fin ${ }^{29}$. De esta manera dejó patente, una vez más, su creencia en la falta de voluntad del Ministerio para llevar a término el cambio emprendido y la justificación de su propia existencia.

En cuanto a las relaciones de la Junta Provisional con el Gobierno impropiamente llamado constitucional ${ }^{30}$, parece lógico pensar que, conforme los ministros iban tomando las riendas de los asuntos de sus propias secretarías, la Junta se hubiera ido retrayendo de participar, cuanto más de mandar, en la mayor parte de ellos. Sin embargo, siguió las mismas pautas que con el anterior gabinete sin cederle ninguna de sus facultades. La característica más sobresaliente de esta relación fue la moderación de la Junta frente a actitudes más drásticas de algunos ministros en el terreno no tanto ideológico como práctico. En consecuencia, las medidas derivadas de las mismas fueron realmente responsabilidad de ellos. Al ministro interino de la Gobernación de la Península y titular de Ultramar, Antonio Porcel, hay que atribuir el decreto de 26 de abril que confinaba en Alava, Vizcaya, Guipúzcoa y Castilla hasta Burgos «a los españoles que estén o hayan estado refugiados en Francia" por haber seguido al gobierno de José Bonaparte, poniendo esta restricción al decreto del 23 del mismo mes, que permitía la entrada de estos refugiados en territorio español sin limitación alguna, acomodándose a lo que las Cortes de Cádiz dictaron sobre el particular ${ }^{31}$. La Junta hizo patente al ministro su total desacuerdo con esta

28. AC, t. 40,$500 ;$ t. 35, 27, sesión de mañana del 15 de marzo.

29 En su oficio la Junta manifestaba que no habia hecho públicos sus trabajos para que fuese el Gobierno quien trasmitiese las noticias necesarias para tranquilizar la opinión y que cualquier dilación en los trabajos sólo conseguiria el descrédito de la Junta y del Gobierno. AC, t. 40, 21, doc. 1481; t. 35, 39v., sesión de tarde del 17 de marzo.

3o Constitucionalmente correspondia al Rey nombrar alibremente" los miembros de su gabinete (Tit. 4, cap. I, art. 171). Excepto el Marqués de las Amarillas, ningún nombramiento reunió ese requisito. Por tanto, el empleo del término “primer gobierno constitucional» se hace en el sentido de gobierno nombrado estando vigente la Constitución de 1812.

31 «Real Decreto de 23 de abril», en Gaceta, 27 de abril de 1820, n. 72, 479. «Real Decreto de 26 de abrilı, en Gaceta, 29 de abril de 1820, n, 73, 488 y 489 . El decreto de 23 de abril fue el resultado de una consulta del ministro a la Junta sobre el regreso solicitado por emigrados a Francia. En ese momento la junta ya advirtió que los decretos de las Cortes sólo eran aplicables a los empleados que sirvieron al Gobierno francés y que permanecieron en las zonas que iban quedando libres, pero no a los que emigraron con el ejército francés. Por tanto, debla permitirseles el regreso. AC, t. 40, 214-217; t. 35, 172 y 172v., sesión de mañana de 21 de abril. 
medida en abierta oposición a la Constitución y a los decretos de las Cortes ${ }^{32}$, pidió que se revocase el decreto del 26 y se publicase una aclaración al del 23, en el sentido de que los refugiados y sus familiares, mientras no mediase sentencia, podían asentarse libremente en el territorio nacional aunque hubieran perdido la ciudadanía como decretaron las Cortes ${ }^{33}$. Esta aclaración nunca tuvo lugar, prevaleciendo, por tanto, la decisión del ministro.

El 9 de mayo el ministro de Gracia y Justicia, Manuel García Herreros, planteo a la Junta el delicado tema de los diputados que firmaron el Manifiesto del 12 de abril de 1814, para poder proceder contra ellos en el sentido señalado por el artículo 172 de la Constitución ${ }^{34}$. La Junta prefería que fueran las Cortes las que tomasen las medidas señaladas en el artículo 172 porque a ellas correspondía juzgar a los diputados, pero propuso la solución intermedia de ponerlos bajo custodia en el caso de peligrar el orden público ${ }^{35}$. El Real Decreto consiguiente se atuvo a estas indicaciones, con la excepción en la reclusión en monasterios o conventos de los diputados obispos por decisión del Rey como se ha visto. La Junta no vela tantos fantasmas como los ministros, ni creía que habia necesidad de tomar medidas drásticas o excepcionales, ni en los casos citados ni en ningún

32 Vuineraba la libertad civil mientras no hubiese sentencia judicial y las Cortes nunca dispusieron el extrañamiento ni el continamiento de quienes sirvieron al "gobierno intruso". Además adujo una razón de tipo humanitario y otra política: confinándolos en determinadas provincias, lo único que se conseguia era mortificarlos más y reunir en ellas una «multitud de descontentos". Exposición de la Junta Provisional al Ministro de la Gobernación de la Península, de 1 de mayo, AC, t. 40, 280-283; t. 35 210bis y 210bis v., sesión de mañana de 1 de mayo.

${ }^{30}$ Las Cortes de Cádiz dispusieron en tres Reales Decretos las medidas a tomar respecto a los empleados que sirvieron al Gobierno francés: «Decreto CLXXXIV sobre varias medidas para el gobierno de las provincias que vayan quedando libres", 11 de agosto de 1812, en Decretos de las Cortes, t. III, 52-54, «Decreto CXCII sobre las medidas para asegurar la confianza de la Nación respecto de los empleados y otras personas públicas», 21 de septiembre de 1812, en Decretos de las Cortes, t. III, 84-87, «Decreto CCIX en el que se prescriben las reglas para la rehabilitación de los empleados que continuaron en sus destinos bajo el gobierno del Rey intruson, 14 de noviembre de 1812, en Decretos de las Cortes, t. III, 166 y 168.

34 Representación y Manifiesto que algunos Diputados a las Cortes ordinarias firmaron..., 12 de abril de 1814. Imprenta de Collado. AC, t. 36, 366-397. La Constitución declaró traidores a quienes aconsejasen o ayudasen al Rey en cualquier tentativa contra la celebración de las Cortes. Oficio del ministro de Gracia y Justicia a la Junta pidiendo informe para proceder con los Diputados que firmaron la Representación y Manifiesto de 12 de abril de 1814, porque, a decir del ministro, "la tranquilidad pública se halla comprometida". $A C, t .36$, 361 y $361 v$.; t. 35,235 y 235v., sesión de tarde del 9 de mayo.

${ }_{35}$ Si peligra el orden público a... el Ministerio no dude en ponerlos bajo custodia con las consideraciones propias de su rango de diputados y para que se vea la moderación que con los delincuentes tiene un gobierno libre». El acuerdo fue adoptado unánimemente por la Junta sobre el informe elaborado por su vocal Mateo Valdemoros y expuesto verbalmente a todos los ministros dado lo delicado del tema. AC, t. 35, 236-238v., sesión de mañana del 10 de mayo; t. 36,360 y $362-365 v$. 
otro ${ }^{36}$. Para ella bastaba con la aplicación de la legislación, pero sin estridencias. Es posible que al no haber sufrido sus miembros consecuencias desagradables al regreso del Rey en el 14, carecieran también del temor exacerbado a un retroceso que experimentaban los «presidiarios" y de la actitud más exaltada de algunos de ellos.

Una segunda característica de las relaciones de la Junta con el Gobierno constitucional fue el buen entendimiento entre ambos cuando los intereses fueron acordes y el Ministerio se le adelantaba en propuestas que convenían al nuevo orden ${ }^{37}$. A cambio, también el Gobierno recibió el apoyo expreso de la Junta cuando situaciones más o menos comprometidas lo requirieron; el apoyo tácito se sobreentendia en el resto de los asuntos ${ }^{38}$.

No faltaron, sin embargo, los problemas, tanto por el choque de facultades de ambos poderes como por la desavenencia con algunos ministros en temas concretos. La primera reclamación formal de sus facultades por parte de la Junta en esta etapa se produjo con motivo de la orden recibida por el General en Jefe del Ejército de Andalucía, Juan O'Donojú, para embarcar tropas en Cádiz con destino a América sin su conocimiento oficial ${ }^{39}$. En consecuencia, el 13 de abril elevó formalmente al Rey su protesta exigiendo su derecho a conocer cualquier medida que tomase el Gobierno «mientras S.M. no se sirva variar o revocar las atribuciones que le

${ }^{36}$ El ministro de Estado, Evaristo Pérez de Castro, quiso poner restricciones a la entrada de extranjeros para evitar perturbaciones de orden público a lo que la Junta se nego, por atentar contra la seguridad individual, aunque se podia tomar precauciones con los que tuvieran «principios perniciosos", y por las ventajas economicas y políticas que suponía el aporte de capitales y la propaganda exterior. AC, t. 36, 116-125v.; t. 35, 314 y $353 v .-354 v$., sesiones de tarde del 5 y de mañana del 14 de junio.

${ }_{37}$ La Junta agradeció al Marqués de las Amarillas la iniciativa de ratificar la orden de las Cortes prohibiendo la concesión de grados militares y aprobó las aclaraciones que le pedía para que la medida fuera interina y no se aplicara en Ultramar. AC, t. 38, 77-78v.; t. 35, 107, 143 y 143v., sesiones de mañana del 4 de abril y de tarde del 13. También aplaudió la propuesta del ministro de Hacienda, José Canga Argüelles para cubrir las vacantes de su ramo con la debida publicidad. $A C, t$. 39, 304-314; t. 35, 151 y 151v., sesión de mañana del 15 de abril.

38 El ministro de la Guerra le manifestó su satisfacción por la respuesta que dio a la Junta de Galicia. Esta pretendia dejar sin efecto la Real Orden del 2 de abril para el licenciamiento en todos los cuerpos de ejército de los cumplidos hasta 1817, con el pretexto de un hipotético peligro exterior y el derecho de las tropas a celebrar la reunión de Cortes. AC, t. $37,270-274 ;$ t. 35,173 y 194, sesiones de mañana del 21 de abril y de tarde del 26 . El mismo ministro vio la actitud tajante y sin contemplaciones de la Junta respecto a los responsables de los sucesos ocurridos en Castilla la Vieja por la negativa de las autoridades militares a reconocer el Nuevo Capitán General nombrado por el Gobierno. Expediente n. 29 del mes de marzo del Ministerio de la Guerra Sobre los sucesos ocurridos en Castilla la Vieja con el Conde de Montijo. AC, t. 37, 317-490bis.

39 El conocimiento de esta noticia, al decir de la Junta, lo obtuvo "por casualidad". Por esta razón decidió elevar al Rey una Exposición con oficio para el ministro de la Guerra. AC, t. 35, 139 y $139 \mathrm{v}$., sesión de tarde del 12 de abril. 
señala el decreto de 9 de marzo" ${ }^{40}$. La reconvención iba dirigida, naturalmente, al ministro de la Guerra quien le contestó el mismo dia que en modo alguno pensaba llevar a término la decisión sin consultar previamente con la Junta y el Consejo de Estado ${ }^{41}$. Aunque no prosperó, la intención de desmarcarse del control de la Junta estaba clara. Dejó constancia también de su manifiesto desacuerdo por las restricciones geográficas impuestas al retorno de los emigrados en Francia ${ }^{42}$. Esta vez el ministro de la Gobernación, Antonio Porcel, logró su próposito.

Consecuencia inevitable del ejercicio por parte de la Junta de su derecho a conocer y emitir dictamen sobre todos los temas de gobierno y de que se cumpliesen sus consejos, fue el enfrentamiento en algún momento con todos y cada uno de los ministros, a excepción del de Estado, Evaristo Pérez de Castro, que se incorporó cuando las relaciones exteriores no ofrecian problemas espinosos. Las respuestas a los requerimientos de la Junta fueron diferentes según los ministros. Mientras que los de Guerra y Marina, Marqués de las Amarillas y Juan Jabat, respectivamente, hicieron valer sus razones frente a la diferente opinión de la Junta, el resto se las calló, tanto si seguían manteniendo su postura, como si rectificaban según el deseo de aquélla o si dejaban languidecer el tema.

La primera y la tercera fueron las actitudes que adoptó Antonio Porcel, siendo ministro interino de Gobernación de la Península, con ocasión del tema de los españoles emigrados a Francia y del restablecimiento del Tribunal Supremo de Salud Pública ${ }^{43}$. Este modo de afrontar las dificultades frente a los criterios de la Junta sin llegar nunca al choque respondia perfectamente al juicio del ministro de la Guerra acerca de su inteligencia y sentido práctico ${ }^{44}$. El ministro de Hacienda José Canga Argüelles, fue reconvenido por la Junta ante el retraso de un mes en contestar a los datos económicos que pidió para solucionar la falta de fondos de la Tesorería

40 Justificó esta reclamación en que la opinión pública estaba convencida de su intervención en todas las medidas tomadas por el Gobierno, lo cual contribula a la tranquilidad de aquélla, pero cargando sobre la Junta responsabilidades en asuntos que ella, como en este caso, no conocia y en que "no se ha excedido ni una sola vez en sus funciones". AC, t. 35, 140-141, sesión de mañana del 13 de abril; Exposición de la Junta Provisional a S.M sobre el envio de tropas a Costa Firme, 13 de abril de 1820; AC, t. 39, 15-16.

41 Toda la labor realizada hasta ese momento iba encaminada a cexplorar voluntades", esto es, qué tropas estarian dispuestas a pasar a Ultramar, y reunir el material necesario para, en caso de ser aprobada esta disposición por el Rey, hacer el envío lo más rápidamente posible. Comunicación del ministro de la Guerra a la Junta el 13 de abril. AC, t. 39, 25-26v.; t. 35,150 , sesión de tarde del 14 de abril.

42 «solo parece buscar en las consultas de la Junta la salvaguardia contra la opinión pública y la odiosidad de algunas medidas que necesariamente hay que tomar". Véase nota 32.

A la reprimenda de la Junta del 9 de mayo por retrasar un tema tan urgente, dada la proximidad del verano y el peligro de epidemias, respondío retrasándolo todavia más y dejándoselo a su sucesor Agustin Argüelles. AC, t. 40, 122-144; t. 35, 104, 211, 211v., 233v., y 234, sesiones de tarde del 3 de abril y 1 de mayo y de mañana del 9 de mayo.

44 «Porcel era el que tenía más talento y más mundo." Giron, op. cit., t. II, 91. 
General y la deficiencia de los mismos ${ }^{45}$. No hubo respuesta concreta del ministro, aunque se tomaron paulatinamente medidas para solucionar la falta de numerario de la Hacienda. El ministro de Gracia y Justicia, Manuel García Herreros, recibió la advertencia de la Junta a propósito de la forma inadecuada de proveer prebendas eclesiásticas y plazas para el Tribunal Supremo y, además, sin consultarle ${ }^{46}$. La constestación de García Herreros fue una nota publicada en la Gaceta con el nombramiento de los nuevos ministros del Tribunal Supremo, sin especificar su calidad de propietarios 0 interinos ${ }^{47}$. Con esta sutileza eludió la moción de la Junta. Ni siquiera el “divino Argüelles», se libró como ministro de la Gobernación de la Península de recibir una reprimenda de la Junta llamándole «por última vez.la atención" el 29 de mayo, para que tomase las medidas necesarias a fin de que el $\mathbf{2 6}$ de junio estuviesen dispuestas todas las oficinas y la redacción del Diario de las Cortes ${ }^{48}$. Por toda respuesta, el 25 de junio le comunicó que el Jefe Político de Madrid le habia entregado las llaves de las puertas principales del salón de Cortes ${ }^{49}$.

Estos cuatro ministros eludieron o acataron los deseos de la Junta como mejor pudieron. Prescindieron o intentaron prescindir de ella en to posible y en lo imposible cedieron silenciosamente. En cambio son notables por todo lo contrario, las actitudes de los dos miembros militares del ga-

45 Oficio del 7 de abril del ministro de Hacienda a la Junta pidiéndole urgentemente su propuesta para remediar la falta de fondos de la Tesorería General. AC, t. 39, 256-260. El 9 de abril la Junta contestó que para dar su opinión necesitaba una serie de datos sobre el estado pormenorizado de ingresos y gastos de la Tesorería General divididos en urgentes y menos urgentes, medidas tomadas para obligar a las provincias a cumplir sus obligaciones con la Hacienda, observación de la ley del máximo y de la prohibición de disfrutar dos sueldos. AC, t. 39, 261-263v.; t. 35, 127v. y 128, sesión de tarde del 9 de abril, «si se toma la molestia de repasar los documentos remitidos por la Junta al ministro y viceversa, ... podrá advertir que el pedido de la Junta está lejos de haber sido satisfechom. Contestación del 11 de mayo acordada por todos los miembros de la Junta al ministro de Hacienda, Canga Argüelles, AC, t. 39, 252-253; t. 35, 242 y $242 v$., sesión de mañana del 11 de mayo.

${ }_{46}$ El tema suscitado por Ballesteros, se discutio ampliamente en su seno en las dos sesiones del 28 de mayo teniendo en cuenta sus propuestas de restablecimiento del Tribunal Supremo y del Consejo de Estado, órgano asesor del ministro en este caso al que correspondia la propuesta para la provisión de estos empleos. AC, t. 35, 293-294, sesiones de mañana y tarde del 28 de mayo. El 5 de junio se aprobó la exposición que desautorizaba la política del ministro en el sentido de que los nuevos cargos para el Tribunal debian ser interinos, como los repuestos del antiguo, para poder examinar su actuación en los últimos seis años y que se podía premiar a los eclesiásticos sin acudir a la provisión de prebendas. Acuerdo de la Junta Provisional del 5 de junio, AC, t. 36, 415-416v.; t. 35, 315v.-320v. sesión de tarde del 5 de junio.

47 Gaceta, 22 de junio de 1820, n. 97, 718-719. Gaceta, 27 de junio de 1820, n. 99, 739.

48 Las oficinas de las Cortes debian estar físicamente dispuestas y atendidas por el personal completo previsto en su reglamento interno en calidad de interino hasta la llegada de los propietarios o el nombramiento de las Cortes para las vacantes. Del mismo modo, debía estar organizada la redacción del Diario y de las actas de las sesiones y la Imprenta Nacional para evitar retrasos en su publicación. AC, t. 40, 651-652; t. 35, 295v. y 296, sesión de mañana del 29 de mayo.

4C, t. 40, 646 y 646v.; t. 35, 396, sesión de mañana del 26 de junio. 
binete, titulares de las carteras de Marina y Guerra, mucho más francas que las del resto y, en consecuencia, menos diplómaticas. El primero, Juan Jabat, tuvo dos enfrentamientos con la Junta con motivo de la defensa que hizo de la dignidad real para que se dejase llegar a Madrid al enviado francés Marqués de Latour du Pin ${ }^{50}$, y de su propia competencia como ministro.de Marina, reclamando el arsenal de la Carraca y el navío San Julián que Antonio Quiroga se negaba a entregar ${ }^{51}$. La Junta se negó rotundamente al citado viaje y dilató el segundo problema hasta la reunión de Cortes ${ }^{52}$. En ambos casos los resultados para Juan Jabat fueron negativos y estuvieron acompañados por el público menoscabo de sus funciones, contribuyendo a ello sin duda el delicado carácter de los temas y la primacía de los intereses políticos.

Ninguna circunstancia es comparable a la del Marqués de las Amarillas, titular de Guerra, ya que los entrentamientos con la Junta hicieron las relaciones muy difíciles. La razón fundamental de ello parece estar en una concepción completamente divergente sobre el tratamiento que debía darse a un ejército que había propiciado el acceso de ambos al poder. Mientras el ministro, que detestaba el que los cambios hubiesen llegado de la mano de un ejército rebelde, pretendia que la disciplina se mantuviese en cualquier caso incluso ante medidas, por desagradables que fueran, que él creía necesarias, la Junta trataba de evitar a toda costa el enfrentamiento con un ejército que a partir del 1 de enero habia dado, y seguía dando, sobradas muestras de efervescencia política. Otras causas más secundarias vendrían a añadirse a la ya señalada, como puede ser el gran número de oportunidades en que el desacuerdo fue posible gracias a la importancia de la institución castrense, la escasa flexibilidad del ministro en muchas y reiteradas ocasiones en que creía estar seguro de tener la razón, la seguridad que le daba el hecho de ser el único ministro llamado por el Rey y la postura vigilante de la Junta respecto a las actividades gubernamentales.

La Real Orden que el 11 de abril partió del Ministerio de la Guerra destituyendo al Marqués de Lazán de la Capitanía General de Aragón, de-

so En la contestación que dio Jabat a la Junta sobre la mala impresión y el disgusto que le habla producido al Rey su sospecha de insinceridad, se puso abiertamente del lado del Soberano. Oficio del 3 de abril del ministro interino del Estado, Juan Jabat, a la Junta. AC, t. 36, 33-40 y t. 35, 102v.-103v., sesión de mañana del 3 de abril.

51 El ministro razonó que no era necesario conservar la linea naval, a la que pertenecia el buque San Julián, guarnecida por Quiroga con la división a su cargo. Dicho navio, junto con otro, debla zarpar para El Callao y, además, en el lugar en que estaba situado y con pólvora en su interior constituía un grave peligro. Por otra parte, la ocupación del Arsenal por otras fuerzas que no eran de Marina, impedía a los Jefes ejercer sus facultades y continuaba el despojo de material. AC, t. 38, 463-466.

62 Contestación del 3 de abril de la Junta al ministro de Estado, AC, t. 36, 28-29v.; t. 35, 104v. y 105, sesión de tarde del 3 de abril. Oficio del 8 de julio de la Junta Provisional al ministro de la Guerra para la entrega del arsenal de la Carraca una vez reunido el Congreso de los Diputados. AC, t. $38,477-478$. 
sencadenó uno de los episodios más tensos en la cúpula del poder ${ }^{53}$. En principio la Junta no puso ninguna objeción a este cambio, probablemente por la conducta poco clara del Marqués de Lazán en los dias que precedieron en Zaragoza a la proclamación de la Constitución el 5 de marzo, y por la actitud arrogante de la Junta de Aragón de la que era Presidente ${ }^{54}$. Pero la alarma cundió entre sus miembros cuando el 21 de abril se presentó el coronel Francisco Romeo con un pliego de la Junta de Aragón solicitando la anulación de la Real Orden y anunciando que estaban al Ilegar reclamaciones semejantes del Ayuntamiento de Zaragoza y de varios ciudadanos, haciendo constar la inquietud reinante en aquella plaza y guarnición ${ }^{55}$. El ministro se plegó a los deseos de la Junta "para evitar males mayores, si es que hay alguno mayor que el desdoro de la autoridad real», "aunque S.M. tuvo fundados motivos para tomar esta medida", y decidió que continuase el Marqués de Lazán en el mando militar de Aragón ${ }^{56}$. El incidente, con ser grave, puesto que se obligaba al ministro a revocar una Real Orden por presiones políticas, no hubiera ido a más a no ser por la torpeza con que el Marqués de Lazán actuó ante la presencia de su sustituto, Miguel de Haro, que desconocía las nuevas órdenes ${ }^{57}$. La Junta tuvo que solicitar del ministro el 6 de mayo la destitución definitiva del Marqués de Lazán "dada la conducta impolítica y sospechosa», demostrada udespués que ella misma pidió su permanencia» ${ }^{58}$. Realmente la actuación del

53 Real Orden de 11 de abril exonerando de la Capitanía General de Aragón al Teniente General Marqués de Lazán y nombrando en su lugar al Mariscal de Campo Miguel de Haro, $A C$, t. 38,156 y 156v.; t. 35, 138, sesión de mañana del 12 de abril.

54 Parece que el dia 6 de marzo siguiente al de la proclamación de la Constitución mantuvo contactos con otras provincias del Norte (gobernadores de los partidos de la provincia y Capitanes Generales de Navarra y Guipúzcoa) para ver cómo se podía sofocar la "marea revolucionaria". Viendo la imposibilidad de éxito de una postura contraria se sumó al carro y se puso a la cabeza de la revolución en Aragón hasta el punto de formar parte como presidente de la Junta constituida el 7. Diario politico de la Junta Gubernativa de Aragón, Zaragoza, Imprenta de Francisco Magallón, jueves 30 de marzo de 1820, n. 6 en AC, t. 41, 169-170v. En el oficio del 1 de abril de la Junta de Aragón se desmentía la conducta irregular del Marqués de Lazán, se erigla en defensa frente a facciosos, abusos, etc. y «no permitirá que el Ministerio tome medidas anticonstitucionales». AC, t. 41, 166 y 166v.; t. 35, 106 y $106 \mathrm{v}$., sesión de mañana del 4 de abril.

55 AC, t. 38, 157-157v.; t. 35, 171v. y 172, sesión de mañana del 21 de abril.

5e Real Orden de 21 de abril para la continuación en el cargo del Marqués de Lazán, AC, t. 41, 180 y 180v.; t. 38, 161-162, doc. 703; t. 35, 174, sesión de tarde del 21 de abril.

${ }_{57}$ Esgrimiendo, como era habitual en él, razones de orden público, lo envió al Castillo de la Aljaferia "no como arrestado sino por su seguridad». Las noticias que recibio la Junta del propio Miguel de Haro sobre la torpe conducta y las sospechas de anticonstitucionalidad del Marqués, las justificaciones nada convincentes del mismo, el mentís del Jefe Político de Zaragoza en cuanto a alteraciones del orden, la existencia de partidas de paisanos armados y de soldados a las órdenes del Capitán General para servicios especiales, etc., abonaron la antigua opinión del ministro. Expediente de los sucesos ocurridos en Zaragoza el 26 de abril con la documentación producida como consecuencia de ellos. AC, t. 38, 182-215.

sa Aconsejaba al mismo tiempo que el medio más oportuno para su separación del mando de la Capitanla General era darle orden de presentarse inemediatamente en Madrid y encargar interinamente de aquella Capitanía al General de cuartel en Aragón que se creyese más oportuno. AC, t. 38, 216 y 216v.; t. 35, 226v. y 227, sesión de tarde del 6 de mayo. 
Capitán General de Aragón nunca fue clara y la Junta Provisional cometió el doble error, no reconocido, de menoscabar la autoridad del ministro de la Guerra y prestar oídos a los cantos de sirena del Marqués de Lazán y sus partidarios. Aunque finalmente rectificó, el daño ya estaba hecho porque su falta de apoyo a la Real Orden de 11 de abril siguió abriendo fisuras dificilmente reparables por mucho que el tiempo, que no la Junta, viniera a dar la razón al Marqués de las Amarillas.

Todavía relacionados con estos hechos tuvo lugar en la noche del 14 de mayo en Zaragoza una serie de alborotos sin más importancia que la representación de la Sociedad Patriótica de Lorencini contra el Marqués de las Amarillas por carecer de la pública confianza ${ }^{59}$. La condescendencia política de la Junta desembocó en una mayor hostilidad contra el ministro de la Guerra, pero hay que señalar que, aunque no reconoció su error, se apresuró a cortar de ráz esta manifestación pública contra el ministro al que, a pesar de todo, defendió de los ataques que le venían de los sectores más radicales como Juntas y Sociedades patrióticas e, incluso, de compañeros del propio gabinete. De modo que, cuando la provisional se disolvió, no tuvo que temer su resistencia, como él mismo reconoció ${ }^{60}$, pero tampoco pudo contar con su apoyo en momentos difíciles y, en definitiva, su dimisión, tantas veces presentada anteriormente, fue inevitable.

Seis fueron las Juntas que se constituyeron antes de adoptar el Rey la Constitución o de conocerse en las provincias este juramento. Fueron por orden cronológico, San Fernando, La Coruña, Oviedo, Zaragoza, Barcelona y Pamplona ${ }^{61}$. Ante una situación de hecho, la Junta Provisional sólo tenia dos alternativas: bien disolver las Juntas Provinciales, bien mantenerlas. Cualquiera de las dos soluciones ofrecía ventajas e inconvenientes. La disolución era jurídicamente lo correcto, puesto que la Constitución

59 El parte del 15 de mayo del Jefe político de Zaragoza, Luis Veyán y la exposición de la Junta de Aragón del 16, hablan del intento de subversión del orden en Zaragoza en la noche del 14 por parte de los mismos sediciosos que intentaron alterar el orden a la llegada de Miguel de Haro para sustituir al Marqués de Lazán que todavía en esa fecha permanecia en Zaragoza. Los desórdenes fueron fácilmente sofocados con el resultado de un solo herido y treinta detenidos. Expediente de los sucesos ocurridos en Zaragoza el 14 de mayo, AC, t. 38, 222-238. Gaceta $E ., 17$ de mayo de 1820 , n. 81, 567-568 y Gaceta, 25 de mayo de 1820, n. 85, 609-610. Oficio del 16 de mayo de los ministros Manuel Garcia Herreros, José Canga Argüelles y Antonio Porcel al presidente de la Junta provisional enviando la representación de la Sociedad Patriótica Lorencini. AC, t. 40, 291-292; t. 35, 261, sesión de mañana del 17 de mayo. Comunicación del 17 de marzo del ministro de la Gobernación. Antonio Porcel, a la Junta de haber pasado al Juez de primera instancia de Madrid el escrito de la Sociedad Patriótica Lorencini para proceder contra sus autores. AC, t. 38, 225-226; t. 35, 267 y 267v., sesión de tarde del 18 de mayo. Contestación de la Junta Provisional a los ministros de Gracia y Justicia, Hacienda y Gobernación. AC, t. 40, 293-294; t. 3, 261 y 262, sesión de mañana del 17 de mayo.

${ }_{60}$ GIRON, op. cit., t. II, 129.

or San Fernando el 3 de febrero, La Coruña, el 21 del mismo mes, Oviedo el 1 de marzo, Zaragoza el 7, Barcelona el 10 y Pamplona el 16. Estas fueron las Juntas que ejercieron verdadero influjo. A las restantes, creadas posteriormente, bien se les ignoro o se mando su disolucion. 
estaba vigente y en ella se atendía al gobierno de las provincias. Por otra parte, las autoridades habian sido ya nombradas por esas mismas Juntas y ratificadas 0 , en su defecto, la autoridad central nombro las que todavia faltaban. Para finales de marzo existia ya un gobierno "de confianza» y había sido cursada la convocatoria a Cortes. Aparentemente, pues, no había razón para la permanencia de unas Juntas a todas luces innecesarias y, si se quiere, hasta ilegales. Calificativo este último aplicable sin duda a partir de la reunión de las Diputaciones provinciales de nueva elección ${ }^{62}$.

Mantenerlas, sin embargo, era la salida política. Aunque suponia duplicidad de competencias, se evitaba el descontento que hubiera podido provocar su disolución. Algunas de esta Juntas hubieran dado por supuesto que esto era una muestra de desconfianza (por menos ya protestaron en este sentido) en quienes se adelantaron a proclamar la Constitución y fueron, por lo mismo, factores fundamentales del éxito. Existía además el peligro de que, por todo esto y viéndose acosadas en una subsistencia que deseaban, hubieran iniciado un nuevo movimiento más radical, no ya contra el poder absoluto, como lo habian hecho entre enero y marzo, sino contra uno liberal que no satisfacia sus espectativas. Por otra parte, la Junta Provisional carecía de fuerza moral para exigir a las demás su disolución cuando su propia situación era bastante similar a la de aquéllas, tanto por las circunstancias de su creación como por las razones de su supervivencia. Su continuación fue, por tanto, más producto del temor que de la necesidad o la legalidad. Era preciso mantenerlas y controlarlas hasta la reunión de Cortes en que, con su disolución pacífica, dejarian de ofrecer peligro y dificultades. Este fue el camino adoptado por la Junta Provisional consciente tanto de la imposibilidad de menospreciar el poder político y militar de las Juntas como de evitar que se pusieran en contacto entre sí para una acción común. Por su parte, las Juntas pretendieron trasladar cronológicamente la intervención que habian tenido en los asuntos internos de su propio ámbito geográfico hasta la reunión de Cortes y extender su influencia a todo el país influyendo en las decisiones gubernamentales.

El primer paso que dieron fue ponerse en contacto con la Junta Provisional para actuar de común acuerdo y aunar esfuerzos en orden a conseguir una buena armonia. Dieron cuenta a la Junta Provisional de las circunstancias de su creación, enviando la documentación al respecto, y de su actuación hasta el momento de conocerse la existencia de aquélla, para obtener su beneplácito y marchar al unísono en el futuro. A todas ellas contestó al Junta Provisional en términos de satisfacción por su conducta

62 Las Cortes de Cádiz mandaron expresamente la disolución de las Juntas de provincia «tan luego como se formen las diputaciones provinciales". "Orden por la que se mandan formar las juntas preparatorias para elegir diputados a Cortes y las diputaciones provinciales: y se suprimen las comisiones de partido luego que estén formados los Ayuntamientos constitucionales", 15 de septiembre de 1812, en Decretos de las Cortes, t. III, 76. 
pasada y por sus intenciones futuras ${ }^{63}$. La Junta de Cataluña fue la única que no estableció este tipo de relaciones con la Provisional porque todas las comunicaciones entre el poder central y el principado se canalizaron a través de las autoridades legítimas, es decir, del Capitán General y de los Jefes Políticos.

El período, en lo que concierne a las Juntas, está marcado por los intentos de convivencia entre la Provisional y las provinciales y por mantener las mejores relaciones posibles entre ambas partes. Para lograr el equilibrio que hiciera factible la gobernabilidad del país, la Junta Provisional tuvo que extremar el tacto con las provinciales haciendo uso a un tiempo de sus mejores artes diplomáticas y de toda su energia. Esta doble actitud fue el origen de las dos tendencias historiográficas que valoran de manera contrapuesta la posición de la Junta Provisional frente a los elementos más extremistas de principios del Trienio. Mientras para unos las concesiones fueron excesivas, para los otros la Junta actuó como verdadera cortapisa de la revolución, llegando a tildarle de «contrarrevolucionaria» ${ }^{64}$. Prototipo de esta relación entre las Juntas provinciales y la Provisional es la establecida con la Junta de Galicia porque en ella se manifestaron con toda claridad las aspiraciones de ambas partes, hasta un punto al que ninguna de las otras llegó, ni necesitaron llegar. Les bastó con ir a remolque y beneficiarse de sus logros o asumir sus limitaciones.

Los vínculos con el poder central a través de la Junta Provisional y de las autoridades provinciales no parecian suficientes a las Juntas y exigieron reiteradamente, hasta conseguirlo, que el Gobierno les trasmitiese directamente las medidas generales que pudieran afectar a los territorios de su influencia a fin de que no se tomaran medidas consideradas por ellas

-3 La de Aragón lo hizo el 14 de marzo (AC, t. 41, 159-160v; contestación de la Junta del 22 de marzo, t. 41, 161-165v.; t. 35, 31v., 32 y 68v., sesiones de mañana del 16 de marzo y de tarde del 22), la de San Fernando en la misma fecha (AC, t. 41, 20 y 20v,; t. 35, 87, sesión de tarde del 28 de marzo, la de Galicia el 15 (AC, t. 41, 24-30v. y 37-48; contestaciones de la Junta de 22 y 24 de marzo, t. 41, 21-22v. y 31-36v.; t. 35, 66v., 68v., 74v. y 89, sesiones del 22 de marzo y de tarde del 24 y 29), la de Navarra el 17 (AC, t. 41, 223-224 y 226-227; constestaciones de la Junta del 23 de marzo, t. 41, 225, 225v., 228 y 228v.; t. 35, 47, 55v. y 72v., sesiones de mañana del 20 y 21 de marzo y de tarde del 23) y la de Asturias el 22 (AC, t. 41, 203-205v. y 207-208v.; contestaciones de la Junta del 1 de abril, t. 41, 206, 206v. 209 y 209v.; t. 35, 88v., sesión de mañana del 29 de marzo).

34 «Pero las personas que la formaron, si bien no podfan dejar muchas veces de ceder a los impulsos del origen de que procedía su nombramiento, evitaron grandes males ... Lástima es, que no pudiendo desprenderse de los intereses que la hablan creado, prestase alguna vez ayuda a los Campeones, mártires de la ruina de aquel régimen, y que entonces no podian renunciar a los trofeos de su triunfo." Miraflores: Apuntes, op. cit., 46 y 47 . "Con este nombramiento (de la Junta) comenzo en Madrid -es decir, a escala nacional- la contrarrevolución". Alberto GIL Novales: Las sociedades patrióticas (1820-1823). Madrid, Tecnos, 1975, t. I, 24. 
como perjudiciales ${ }^{65}$. En este nivel limitado consiguieron, además, la confirmación de las autoridades civiles y militares nombradas por ellas de acuerdo con la política general adoptada al respecto y llegando a la desobediencia cuando el poder central intentó alguna variación. En estos casos se puso de manifiesto tanto la intención de no obedecer aquellas medidas con las que no estuviesen de acuerdo, como la desconfianza en la Junta Provisional, el Gobierno y el Rey. La Junta de Galicia se negó a aceptar el nombramiento de Pedro Agar como Capitán General, en lugar del Coronel Carlos Espinosa ${ }^{66}$. La de Navarra consiguió la sustitución del Virrey Conde de Ezpeleta por Espoz y Mina en la Capitania General, pero rechazó el nombramiento de Miguel Escudero como jefe Político y dio posesión del cargo a su vocal Pedro Clemente Ligués ${ }^{67}$. La de Aragón logró

65 Exposiciones del 15 y 25 de marzo de la Junta de Galicia a la Provisional. AC, t. 41, 23-30v. y $49-50 \mathrm{v}$.; t. $35,66 \mathrm{v}$. y 89 , sesiones de mañana y tarde del 22 de marzo y de tarde del 29. Exposición del 8 de abril de la Junta de Asturias a la Provisional. AC, t. 41, 210-211; t. 35 , 149 y $149 v$., sesión de mañana del 14 de abril.

${ }_{66}$ En el Acta acordada en sesión de hoy 1. de abril de 1820 la Junta de Galicia tomó la resolución de que Pedro Agar se encargarse del mando político, que ya lo ejercía "en unión de la Junta" desde el 22 de febrero, al tiempo que complacía al Rey y le daba una muestra de deferencia. En cuanto al mando militar «no debe hacerse novedad como dado por el pueblo" que se lo concedió primero a Carlos Espinosa, que legó en Félix Acevedo, y tornó al primero a la muerte de éste. Se añadió la fórmula de cortesía de agradecer al Rey el deseo de reunir los dos cargos en su Presidente. AC, t. 41, 78 y 78v. Oficio del 1 de abril de Pedro Agar al ministro de la Guerra que remite a la Junta Provisional comunicándole la disposición de la Junta de Galicia de que Carlos Espinosa continúe en el mando militar. AC, t. 37, 285286; t. 35, 122v. y 123, sesión de mañana del 8 de abril. La contestación del 1 de abril de la Junta de Galicia a la Provisional no dejaba lugar a dudas sobre sus intenciones. Aunque la buena fe demostrada por el Rey le inclinase a dimitir de su autoridad, no podría hacerlo porque peligraría la credibilidad de la Junta Provisional "y de las personas que S.M. tiene cerca. entre las que hay sospechosas por su conducta versátil». El nombramiento de Pedro Agar habia tenido consecuencias desagradables para él porque se interpretó como debilidad de la Junta de Galicia frente al poder central. Advertia, por fin, lo indispensable que era que la Junta Provisional fuera consciente de la necesidad de advertir a los ministros uque no propongan al Rey empleados para la provincia de Galicia donde hay personas beneméritas que pueden discernir con justicia". AC, t. 41, 67-68; t. 35, 120 y 120v., sesión de tarde del 7 de abril.

${ }_{67}$ Oficio del 27 de marzo de la Junta Provisional al Ministro de la Gobernación apoyando la exposición de la Junta de Navarra del 24 de marzo para que Miguel Escudero no ejerza el cargo de Jefe político. AC, t. 40, 438 y 438v,; t. 35, 82, sesión de mañana del 27 de marzo.; Exposición del 29 de marzo de la Junta de Navarra a la Provisional. AC, t. 41, 230 y 230v.; t. 35, 96v. y 97 , sesion de mañana del 1 de abril. A Escudero no se le admitió por haber firmado en 1814, tras el decreto del 4 del mismo mes, un acta como Presidente de la Diputación felicitando a Fernando VII por haber abolido la legislación gaditana. Francisco EsPoz y MinA: Memoria del general don Francisco Espoz y Mina. Madrid, Atlas, 1962 en BAE, t. CXLVI, 240. Real Orden del 31 de marzo del ministro de la Gobernación enviada a la Junta Provisional confiriendo el cargo de Jefe Politico de Navarra a Manuel José Quintana, encargándoselo interinamente a Pedro Clemente Liqués en caso de la salida de aquél para Madrid y a la espera de la propuesta de la Junta de Navarra. AC, t. 40, 430-440v.; t. 35, 94v., sesión de tarde del 31 de marzo. Oficio del 7 de abril de la Junta de Navarra a la Provisional dando cuenta de su futura remodelación y del nombramiento de Jefe Politico. AC, t. 41, 241-242v.: t. 35, 136, sesión de tarde del 11 de abril. Contestación del 13 de abril de la Junta Provisional a la disuelta Junta de Navarra prometiendo su apoyo para el nombramiento de Liqués como Jefe Politico en propiedad. AC, t. 41, 243; t. 35, 136, sesión de tarde del 11 de abril. 
que no se hiciese efectiva la primera destitución de su Capitán General el Marqués de Lazán, aunque, como se ha visto, no pudo evitar que a la postre se llevase a cabo con su propio consentimiento, dada la actuación de $\mathrm{Pa}-$ lafox.

La reacción del ministro de la Gobernación y de la Junta ante los hechos protagonizados especialmente por la Junta de Galicia son una muestra de su propia posición. Aquél temía que el ejemplo cundiese en las demás provincias y en Ultramar, como ocurrió en $1808^{68}$. La Junta, por su parte, nos dejó, en su contestación al ministro, un patente y patético testimonio de la debilidad y limitación del poder y del papel al que debian ajustarse las Juntas provinciales hasta la reunión de Cortes. Éste no debía de ser otro que limitar sus atribuciones al cumplimiento de las órdenes del Gobierno, seguir su misma dirección y hacerle presente cuanto creyesen conveniente para sus respectivas provincias. La única manera de conseguirlo, a su parecer, era el "consejo y el exhorto" dadas las circunstancias del momento y en el caso de la Junta de Galicia, evitar enviarle directamente órdenes "que se oponen al sistema que tiene adoptado y que parece empeñada en seguir» para evitar desobediencias que requirirían medidas más enérgicas y de consecuencias incalculables ${ }^{69}$. Este fue el sentido de la respuesta a la Junta de Galicia, pero en términos más firmes, sin dejar traslucir el peligro que suponia su desobediencia y la debilidad del sistema para hacerle frente $y$, al mismo tiempo, con la concesión de aceptar a las Juntas como mediadoras para dar a conocer las necesidades de sus provincias y las personas de su confianza para ocupar los cargos en ellas ${ }^{70}$.

68 Oficio del 8 de abril del ministro de la Gobernación a la Junta Provisional comentando los escritos de la de Galicia que le envió el 7 de abril y pidiéndole consultas para remediar la situación. AC, t. 41, 65 y 135-136; t. 35, 120v., sesión de tarde del 7 de abril.

69 En medio de todo, la Junta Provisional manifestaba su alivio por el reconocimiento por la de Galicia de Pedro Agar como Jefe Político porque «no le desembarazarán en sus atribuciones, especialmente en la elección de Diputados» y porque el ministro de la Guerra no le había nombrado Capitán General con lo que podía comunicarle el de Gobernación esta contestación. Exposición del 8 de abril de la Junta Provisional al Ministro de la Gobernación con sus reflexiones sobre la del 1 de abril de la Junta de Galicia. AC, t. 41, 69-72; t. 35, 121122v. sesión de mañana del 8 de abril.

70 Después de mostrarle su sorpresa ante la reacción por el nombramiento de su Presidente como Capitán General, cuando crela que era una prueba de la voluntad del Rey, de cuya buena fe "nadie puede dudar», y su ignorancia de que «el pueblo de Galicia no tuviese la confianza de su seguridad más que en el Coronel Carlos Espinosa», pasaba a hacerle algunas "observaciones" para conseguir un sistema uniforme en todas las provincias, identificadas con el Trono, y para que las potencias exteriores no pudieran pensar en una disociación «entre los pueblos y el Rey», o lo que es lo mismo entre la revolución y la Corona. Lo que se le pedía realmente era limitar sus atribuciones a la marcha general del pais y del Gobierno modificando para ello, si fuera necesario, su autoridad. Apoyaba esta solicitud en que las circunstancias que dieron lugar a la creación de las Juntas habian variado desde el momento en que el Rey habla aceptado "la voluntad del pueblo", que las demás Juntas ya lo habian hecho y solicitado del Rey la aprobación de sus trabajos y confirmación de los nombramientos hechos y que ninguna habia sido defraudada. Oficio del 10 de abril de la Junta Provisional a la de Galicia en contestación a su exposición del 1 de abril. AC, t. 41, 73-76v., doc. 1823; t. 35, 120v. y 129-133v., sesiones de tarde del 7 de abril y de mañana del 10 . Este 
El forcejeo por falta de entendimiento y confianza entre la Junta de Galicia y el poder central, personificado de facto en la Junta Provisional, puesto de manifiesto en temas como la comunicación directa de las órdenes del Gobierno para velar por su cumplimiento, el nombramiento de autoridades, la organización del ejército de Galicia o la petición de personalidades de confianza junto al Rey, dio lugar no sólo a una correspondencia cada vez más agria y destemplada por ambas partes, sino que puso en marcha un dispositivo que la Junta Provisional estimó peligrosísimo. Mucho más peligroso para la estabilidad del nuevo régimen que el empeño de la Junta de Galicia por mantener su autonomia al margen del poder central y el ejemplo que para el resto de las Juntas podía suponer. La nueva pretensión de la Junta de Galicia consistió nada menos que en tener una representación permanente en la Provisional, junto con el resto de las Juntas. En otras palabras, la formación de una segunda versión de la Junta Central ${ }^{71}$. Lo que la Junta de Galicia planteó, como hecho consumado y comunicado al resto para que siguieran su iniciativa, fue el retorno a una situación semejante en lo político a la de 1808 , de consecuencias imprevisibles porque una Junta asi formada contaría con la mayoría absoluta de miembros pertenecientes a la tendencia más exaltada o revolucionaria que acabaria abrogándose facultades ejecutivas y legislativas. La rotunda negativa a asociar vocales provinciales se basó más en razones técnicas que en las verdaderas razones de fondo, reconocidas a posteriori por los «gravísimos inconvenientes que pronto se presentarian" ${ }^{72}$.

fue el pliego que la Junta Provisional envió a la de Galicia con Evaristo San Miguel, que comunico haberla entregado el 17 de abril, y la sorpresa que causó la duda de su adhesión al Trono Constitucional. Oficio del $18 \mathrm{de}$ abril de Evaristo San Miguel a la Junta Provisional. $A C$, t. 41, 137 y 137v.; t. 35, 177v., sesión de tarde del 22 de abril.

${ }^{71}$ El 8 de abril nombró a Joaquín Fondevila, residente en Madrid, como su representante ante el Rey y la Junta Provisional para evitar demoras en las consultas. Oficio de/ 8 de abril de la Junta de Galicia a la Provisional. AC, t. 41, 134; t. 35, 151v., sesión de mañana del 15 de abril. El 15 de abril, creyendo insuficiente la representación citada nombró a dos de sus vocales, José Maria del Busto y Manuel Latre, con plenos poderes para asociarse a la Junta Provisional y tomar parte en sus deliberaciones y acuerdos. Oficio del 15 de abril de la Junta de Galicia a la Provisional. AC, t. 41, 156; t. 35, 172v. y 173, sesión de mañana del 21 de abril. La Junta de Galicia se quejaba de que habiendo sido la primera en intentar "la buena inteligencia y la unidad», se la tuviera que advertir precisamente a ella de esta necesidad. Afirmaba que a su situación de aislamiento, sin órdenes del Gobierno para trasmitir a la provincia y sin saber siquiera el efecto de la felicitación que envió al Rey a través de la Junta Provisional, se respondía con calumnias. En cuanto a la provisión de empleos dirigió un duro ataque a «la acalorada guerra ... que acosa a la Corte» y al «enjambre de pretendientes que sitian al Monarcam, cosa que en Galicia no había ocurrido porque en los que ella hizo no mediaba ambición alguna y se limitaron a los estrictamente necesarios. Esto no debia mover a envidia «porque por más que escogiesen, siempre serian ignorantes en las cosas de Galicia y de sus gentes". Contestación del 19 de abril de la Junta de Galicia al oficio de la Junta Provisional del 10 de abril, enviada por Evaristo San Miguel. AC, t. 41, 138-141v., doc. 1829; t. $35,177 \mathrm{v}$., sesión de tarde del 22 de abril.

${ }_{72}$ Oficio del 22 de abril de la Junta Provisional al Ministro de la Gobernación manifestando la irregularidad y el perjuicio del envio de vocales por la Junta de Galicia. AC, t. 41, 142; t. 35, 172v. y 173, sesión de mañana del 21 de abril. Contestación del 22 de abril de la 
Las concesiones a las Juntas, con ser importantes, nunca llegaron al punto de quiebra que pusiese en peligro el proceso de transición hacia un régimen moderado. El equilibrio se saldó de forma favorable a este proposito, lo cual no quiere decir que para el futuro desapareciera la naciente corriente exaltada y que, incluso, saliera fortalecida por las conquistas realizadas. La disolución pacífica de las Juntas fue, por tanto, la solución aparente de un problema.

Las Sociedades Patrióticas ${ }^{73}$, reuniones de ciudadanos para la discusión política, que proliferaron en España durante el Trienio Liberal, se autoconsideraron órganos creadores y difusores de opinión pública. Como quisieron tener el monopolio de la opinión y ser los portavoces del «pueblo», no se limitaron a la discusión más o menos acalorada de los temas políticos y a su difusión impresa, sino que elevaron al Gobierno y a la Junta Provisional peticiones, exigencias, críticas, etc. La confusión entre opinión y soberanía les llevó a sentirse con derecho a ser escuchadas incluso en temas de exclusiva competencia del Gobierno o del Rey, y a la pura frustración al comprobar que apenas se les tenía en cuenta. Por su parte, la Junta Provisional soportó con estoicismo las críticas de las Sociedades patrióticas, como las de las Juntas provinciales, incluso las referidas a su manera de proceder, siempre y cuando no rebasasen ciertos límites: el orden público y decoro del Gobierno para las primeras y la obediencia al poder central para las segundas. Sin embargo, no dejó de aprovechar la parte positiva, esto es, la fuerza que para sus argumentos le podía dar el respaldo de la opinión pública utilizando, como hacian las propias Sociedades, la parte por el todo. Nunca hubo respuestas escritas a las peticiones de las Sociedades Patrióticas de forma que fueron los hechos los que dieron a conocer el grado de aceptación o rechazo de aquéllas por parte de la Junta Provisional y el Gobierno.

A pesar de esta actitud, sería erróneo, no obstante, pensar en displicencia o indiferencia de la Junta. Por el contrario, era sensible a la opinión pública y al juicio que de ella se pudiera formar llegando incluso a

Junta Provisional a la de Galicia en respuestas a su exposición del 15 de abril. AC, t. 41, $57-64$; t. 35, 172v. y 173, sesión de mañana del 21 de abril. Los fundamentos de la oposición de la Junta Provisional era la diferencia de atribuciones entre ella y las Juntas provinciales, su seguridad de haber cumplido con los deberes que se le encomendaron y la absoluta sinceridad del Rey como los más importantes, pero no los principales. Secundariamente señalaba la igualdad de derechos que al respecto tendrán las otras Juntas con lo que el proceso de elección de vocales se alargaría tanto que ya no merecería la pena por la proximidad de la celebración de las Cortes. Además, la representación de las Juntas provinciales existentes frente al resto del pais, que carecía de ellas, sembraria la discordia y la desconfianza interior y exterior «cuando se prepara la reunión de las Cortes, única representación nacional». Manifiesto de la Junta Provisional a las Cortes, en Miraflores: Documentos, op. cit., 127 y 128.

${ }_{73}$ Sobre sus antecedentes, tipologia, organización, etc. así como su evolución, proliferación y órganos en el Trienio Liberal es de obligada consulta la obra de Alberto GIL NovALES, op. cit., aunque su interpretación sobre este fenómeno esté muy alejada de la que se mantiene en este trabajo. 
abrigar el temor de que no se correspondiese con sus verdaderas intenciones. Pero, con todo, en ningún momento dio públicas explicaciones de su política, no sólo porque las circunstancias eran excepcionales, sino porque lo excepcional era su poder. Su conocimiento hubiera redundado en perjuicio de la imagen del Rey y del Gobierno y ya hemos visto cómo esto la Junta lo evitó a toda costa.

El hilo conductor de todas las comunicaciones de las Sociedades Patrióticas a la Junta Provisional fue el miedo a una reacción absolutista viniera de donde viniera: Rey, Gobierno, clero, ejército, reunión de anticonstitucionales, etc. Este tema de fondo, al que se subordinaban todos los demás, les hizo erigirse en portavoces de cuanta noticia o rumor, que creyeran ponía el sistema en peligro, llegaba a ellas y les movió a exigencias cada vez más radicales hasta poner en peligro su propia existencia.

A pesar de todo, influyeron en la decisión de acelerar el nombramiento de un gabinete constitucional, miembros que debian componer el Tribunal Supremo, medidas contra la Compañía de Jesús, expulsión de Madrid de personas politicamente indeseables, etc. ${ }^{74}$ Sin embargo, no se puede hablar de concesiones por parte de la Junta Provisional en estas y otras decisiones, sino simplemente de aprovechamiento de la presión ejercida por las Sociedades para sus propios intereses tanto en cuanto a ritmo como a profundidad. En cambio consiguieron a través del Ministerio, más vulnerable a la opinión pública por su propia tendencia y por temor a una nueva reacción absolutista, arrancar medidas en consonancia con su forma de entender la revolución. En esta línea se situó el confinamiento de los diputados «persas" de las Cortes de 1814 o la prohibición a los refugiados en Francia de pasar la línea del Ebro, como se ha señalado. Por el contrario, nunca consiguieron otra serie de pretensiones como la publicación de las deliberaciones de la Junta Provisional ${ }^{75}$ o la petición de dimisión del ministro de la Guerra, Marqués de las Amarillas, que estuvo a punto de provocar una crisis de gobierno ${ }^{76}$ y a la que siguió un proceso judicial y la práctica desaparición de la Sociedad de Lorencini.

74 Exposiciones del 13 y 14 de marzo de varios ciudadanos de Madrid a la Junta Provisional. AC, t. 41, 300-304; t. 35, 29v, sesión del 15 de marzo. AC. t. 35, 18-19, 21-22v., 23-28, sesiones del 13 y 14 de marzo. Expediente del 27 de marzo al 29 de abril relativo a las temporalidades de la Compañia de Jesús. AC, t. 36, 253-259v.

75 Exposición del 11 de abril de los ciudadanos de las Sociedades Patrióticas de Lorencini y San Sebastián a la Junta Provisional. AC, t. 41, 248-256 y t. 35, 149 y 149v., sesión de mañana del 14 de abril.

${ }_{70}$ Representación del 16 de mayo de la Sociedad Patriótica de Lorencini a S.M. manifestando la falta de confianza pública en el ministro de la Guerra y pidiendo su dimisión, en GIL Novales, op. cit., t. I, 71. Oficio de 16 de mayo de los ministros de Gracia y Justicia, Gobernación y Hacienda, Manuel Garcia Herreros, Antonio Porcel y José Canga Argüelles respectivamente, a la Junta Provincial. AC, t. 40, 291-292; t. 35, 261, sesión de mañana del 17 de mayo. Contestación del 17 de mayo de la Junta Provisional a los ministros de Gracia y Justicia, Gobernación y Hacienda sobre la Sociedad Patriotica de Lorencini. AC, t. 40, 293294; t. 35, 261-262, sesión de mañana del 17 de mayo. 
Las relaciones entre el poder y las Sociedades Patribticas no se pueden entender sin considerar dos cuestiones básicas colegibles de la propia documentación. Por parte de la Junta Provisional y de los liberales de la primera generación, ministros incluidos, fue superior el interés por mantener el orden público que la libertad de expresión. De tal modo libertad y orden fueron categorias inseparables que llegado el momento de ver peligrar el segundo, no dudó la Junta en dar a la Sociedad Lorencini el mismo trato que a los autores de desórdenes de signo absolutista, como ocurrió, por ejemplo, con las destrucciones de lápidas de la Constitución. Su preocupación se dirigió al mantenimiento del orden más que a las peticiones en si, aunque fuera la dimisión de un ministro constitucional. También llama poderosamente la atención el mayor temor de la Junta Provisional al exceso revolucionario que a los movimientos reacccionarios. Consciente o inconscientemente éste fue el mecanismo por el que las Sociedades arrancaron concesiones del Gobierno y de la Junta. Ante los movimientos reaccionarios siempre contestó con palabras tranquilizadoras, como si una vez establecido el orden constitucional nunca pudieran ponerlo en peligro, y ordenando la aplicación de la ley. En cambio, lanzó constantes advertencias contra el «exceso de entusiasmo» sin perder de vista el ejemplo revolucionario francés ${ }^{77}$.

La disparidad entre Junta y Sociedades en estos dos puntos no podía ser mayor. Para las Sociedades la libertad de expresión era su propio fundamento, sin la cual su existencia no tenía razón de ser, y a él se supeditaba no sólo el orden, sino incluso el respeto al Rey y al Gobierno. Por otra parte, al temor al exceso de la Junta contraponian su exceso de confianza y el propio temor a un retroceso político. Las divergencias, por tanto, siendo todos liberales, no pueden extrañar, aunque las diferencias en este momento eran más de método y procedimiento en la actuación política que ideológica. Frente a la tolerancia, lentitud y secretismo que achacaban las Sociedades a la Junta se oponía el temor de ésta a los excesos, y si bien no puede hablarse todavia strictu sensu de moderados y exaltados ya empezaron entonces a perfilarse las dos tendencias y a sentar las bases para su escisión posterior.

El ejército, al contrario que Juntas y Sociedades, no necesitó hacer valer sus pretensiones porque el poder central conocía suficientemente cuáles eran éstas y la fuerza con que contaba para conseguirlas. La punta

77 Con motivo del aniversario de la Constitución la Junta publicó una proclama señalando los logros conseguidos en orden a la instalación del sistema constitucional y advirtiendo que "la impaciencia, llevada al extremo y agitada por espiritus poco reflexivos, es un arma para desunir la opinión, excitando temores y desconfianzas, porque tienen en continua fluctuación a la opinión pública. Esto lleva a los hombres buenos a la fatiga y abandono del timón del Estado con daños irreparables para el pais». Recordaba, además, las revoluciones "precipitadas e imprudentes" como la experiencia francesa. Manifiesto del 19 de marzo de la Junta Provisional a la Nación. AC, t. 41, 408; t. 35, 41, sesión de mañana del 18 de marzo. 
de lanza de esta institución fue el llamado Ejército de la Isla, es decir, la parte del ejército expedicionario que destinado a Ultramar se sublevó en la baja Andalucía el 1 de enero de 1820. En primer lugar, consiguib para si la permanencia sobre las armas cuando su subsistencia ya no tenia razón de ser porque había desaparecido la causa por la que se le había reunido. Por extensión, el resto del ejército que favoreció el éxito de la revolución a lo largo del país, permaneció en los mismos lugares en que se sublevó. Su gran peso específico procedía del prestigio alcanzado por el Ejército de la Isla considerado tan fundamental en ciertos ambientes liberales como para alcanzar la categoria de mito, aunque sus logros militares fueron muy limitados. Por otra parte, cualquier movimiento de estas fuerzas hubiera arrastrado a las restantes con consecuencias incalculables para la revolución moderada que se pretendía hacer. Por estas causas la disolución del Ejército de la Isla o el traslado de tropas a otros lugares apartándolas de las poblaciones que les sustentaban, se demostraron políticamente imposibles, por más que éstos fueran los deseos del Gobierno, especialmente del ministro de la Guerra, y de la Junta Provisional.

A partir de estas premisas, la política que se llevó a cabo consistió en contrariar lo menos posible a jefes y oficiales cuando no en adularlos y halagarlos, tanto si su conducta era disciplinada o acorde con la Constitución, como si no. Por contraste, se evitó poner en sus manos el más mínimo poder tanto del Gobierno central como de la cúspide militar, lo cual se consiguió inexplicablemente, a excepción de las capitanías generales donde se nombró la autoridad militar antes de que el Rey jurase la Constitución. Pero esta fue una política de corto alcance: hasta la reunión de las Cortes y para atravesar la etapa de transición sin convulsiones en la creencia de que lograda la representación nacional, desparecerian los problemas ${ }^{78}$. La realidad se mostraría bien diferente: la falta de participación de las fuerzas que propiciaron el retorno liberal y su no incorporación a las tareas de gobierno iniciaron el distanciamiento entre las dos tendencias. Aunque todavía no se pueda hablar en esas fechas de división o abierto enfrentamiento, si puede afirmarse que el germen existía y que el mantenimiento de estas fuerzas totalmente al margen, considerado un éxito por la Junta y el Gobierno, se demostró a la larga como un craso error político. Este menosprecio de una corriente todavía incipiente fue la razón a corto plazo de la dimisión del ministro de la Guerra, a medio plazo de la división de la familia liberal y, a la larga, uno de los factores que provocaron el fracaso del Trienio ${ }^{79}$.

79 La documentación relativa a la problemática del Ejército en todos sus detalles se encuentra en el $A C$, t. 37,518 págs. y t. 38, 776 págs.

${ }_{79}$ Charles WENTZ FeHRENBACH: «Moderados and Exaltados: The Liberal Opposition to Ferdinand VII, 1814-1823", en The Hispanic American Historical Review, February 1970, 52-69. Utiliza para la descripción de la época las Actas de la Junta Provisional, pero de forma fragmentaria de modo que no alcanza a vislumbrar que la primera división seria entre los liberales con la disolución del Ejército de la Isla quedó ya planteada en los meses precendentes, aunque la chispa saltara después. 
Al parecer los liberales del 12 habian perdido la audacia, que entonces no les faltó, para intentar una «huida hacia adelante»; se encontraron instalados en el poder e incapaces de dar cabida a los autores materiales de este regalo, que, a juzgar por los antecedentes, hubieran aceptado de buen grado. Por su parte, los revolucionarios contaban con datos suficientes como para poder saber que el método más eficaz para conseguir sus propósitos era amenazar o provocar desórdenes ante los que el poder ya había cedido. El Parlamento sería para ellos una nueva palataforma de poder. 